\title{
EFEKTIFITAS PEMBELAJARAN PROBLEM BASED LEARNING BERBANTUAN VIRTUAL LABORATORY DITINJAU DARI HASIL BELAJAR DAN KEMAMPUAN BERPIKIR LOGIS MATEMATIKA SISWA SMP
}

\author{
Heny Sri Astutik ${ }^{1}$, Putri Aniningsih ${ }^{2}$ \\ Universitas Pendidikan Muhammadiyah Sorong, Papua Barat ${ }^{1,2}$ \\ Email: henysriastutik@gmail.com
}

\begin{abstract}
This research aims to test the effectiveness of the Problem Based Learning (PBL) learning model. The subjects of this study were 38 of eighth-grade students of Muhammadiyah Middle School Aimas, Sorong Regency, West Papua. The research used a quasi-experimental method, using Nonequivalent Control Group Design. The experimental class uses the PBL learning model by applying VR Math, while the learning control class is carried out with conventional models, namely lectures and frequently asked questions. The instruments used for data collection were observation, tests, and questionnaires. The test instrument consisted of learning outcomes tests and students' logical thinking abilities. The other instrument is questionnaire for students' responses to PBL learning using the VR Math application. The results of the study concluded that the PBL learning model using the VR Math application is not effective if measured from student learning outcomes, conversely, the PBL learning model uses the VR Math application effectively when considered from students' logical thinking abilities.
\end{abstract}

Keywods: Problem Based Learning, VR Math, Logical Thinking Capabilities.

\section{PENDAHULUAN}

Pendidikan diharapkan selalu berkembang sesuai dengan perkembangan Ilmu Pengetahuan dan Teknologi. Kementerian Pendidikan dan Kebudayaan dalam salah satu artikel menyatakan bahwa pendidikan perlu mengikuti perkembangan teknologi pada masyarakat. Abad 21 ini, pendidikan menjadi sangat penting untuk menjamin peserta didik memiliki keterampilan belajar dan berinovasi, keterampilan menggunakan teknologi dan media informasi, serta dapat bekerja, dan bertahan menggunakan keterampilan untuk hidup (life skills). Konsep pendidikan abad 21 telah diadaptasi oleh Kementerian Pendidikan dan Kebudayaan Republik Indonesia untuk mengembangkan kurikulum baru untuk Sekolah Dasar (SD), Sekolah Menengah Pertama (SMP), Sekolah Menengah Atas (SMA), dan Sekolah Menengah Kejuruan (SMK). Kecakapan yang harus 
dicapai pada abad 21 yaitu kecakapan belajar dan inovasi (kreatif, kritis, inovasi, komunikasi, kolaborasi). Lebih lanjut, kecakapan informasi, media dan teknologi (literasi informasi, literasi media, literasi teknologi informasi), juga merupakan kecakaan yang perlu dicapai dalam pendidikan pada abad 21 ini.

Menurut kutipan yang dipublikasikan oleh Kemendikbud pada tanggal 17 September 2016, Kepala Badan Penelitian dan Pengembangan (Balitbang) Totok Suprayitno menyatakan bahwa "Ujian Nasional (UN) perbaikan yang telah diselenggarakan sejak tanggal 29 Agustus samapai dengan 7 September 2016 dan diikuti hampir 50.000 peserta, hari ini mereka dapat melihat hasil ujiannya baik secara online ataupun di sekolah tempat mereka ujian." Data tersebut merupakan salah satu bukti bahwa tingkat kelulusan di Indonesia masih rendah dilihat dari banyaknya peserta UN perbaikan tahun 2016.

Undang-undang Nomor 20 Tahun 2003 tentang Sistem Pendidikan Nasional menyatakan bahwa:

"Pendidikan adalah usaha sadar dan terencana untuk mewujudkan suasana belajar dan proses pembelajaran agar peserta didik secara aktif mengembangkan potensi dirinya untuk memiliki kekuatan spiritual, keagamaan, pengendalian diri, kepribadian, kecerdasan, akhlak mulia, serta keterampilan yang diperlukan dirinya, masyarakat, bangsa dan negara”.

Berdasarkan ketentuan dalam undang-undangan tersebut, maka dalam pembelajaran, siswa harus lebih aktif dalam pemecahan masalah dan mengembangkan potensi dari masing-masing dirinya.

Lebih lanjut, permasalahan dalam pembelajaran tersebut juga merupakan hal yang penting dalam pembelajaran matematika. Hal ini disebabkan karena berbagai fenomena dalam kehidupan sehari-hari dapat diselesaikan dengan menggunakan matematika. Menurut Haryono dan Tanujaya (2018), matematika mempunyai peranan penting dalam perkembangan ilmu pengetahuan dan teknologi. Lebih lanjut Agustin (2016) menyatakan bahwa bidang ilmu pengetahuan, yang tidak terlepas dari pengaruh dari matematika, antara lain pendidikan, kesehatan, dan teknologi.

Banyaknya penggunaan ilmu matematika dalam kehidupan sehari-hari ini yang membuat pendidik harus memikirkan cara agar siswa mampu berfikir secara logis agar bisa diterapkan dikehidupan sehari-hari. Perkebangan zaman yang semakin hari semakin maju tersebut yang membuat pendidik di zaman sekarang harus melakukan berbagai 
inovasi agar generasi penerus nanti dapat mengikuti perkembangan yang terjadi. Salah satu caranya yang dapat dilakukan oleh pendidik, yaitu dengan menerapkan model atau metode pembelajaran yang lebih mengedepankan kreativitas siswa dalam pembelajaran. Globalisasi zaman inilah yang menjadi tantangan yang akan menguntungkan tetapi meresakan bagi masyarakat dunia, hal itu dikarenakan globalisasi membuat dunia semakin mudah namun privasi semakin bebas.

Namun demikian, data yang diambil dari observasi yang dilakukan di SMP Muhammadiyah Aimas bulan September 2017 menunjukan bahwa SMP Muhammadiyah Aimas masih menggunakan Kurikulum Tingkat Satuan Pendidikan (KTSP) 2006 dengan tingkat ketuntasan nilai matematika khususnya kelas VIII masih sangat rendah, dari 20 siswa yang ada dikelas hanya 1-2\% yang memenuhi nilai ketuntasan minimal. Hasil yang diperoleh tersebut masih jauh dari harapan untuk menghasilkan lulusan peserta didik yang sesuai dengan kebutuhan masyarakat dan perkembangan ilmu pengetahuan dan teknologi.

Di lain pihak, perkembangan zaman yang semakin maju akibat pengaruh globalisasi menuntut guru harus lebih inovatif dalam memberikan pembelajaran. Dewasa ini perkembangan dunia internet yang sangat pesat, membawa dampak terhadap menyempitnya jarak antar bangsa di dunia yang biasa disebut globalisasi. Pengaruh globalisasi memberikan dampak yang sangat signifikan dibidang pendidikan kita harus senantiasa mengikuti perkembangan tersebut supaya pendidikan negara kita tetap maju. Rendahnya minat belajar siswa yang berpengaruh pada hasil belajar siswa menjadi masalah serius sehingga pendidik membutuhkan langkah-langkah konkrit untuk mencari penyelesainnya (Siing: 2017).

Langkah konkrit yang dapat dilakukan oleh pendidik adalah memilih model pembelajaran yang tepat dalam pembelajaran. Pemilihan model pembelajaran yang tepat menurut Joice, Weil, dan Calhoun (2011), merupakan salah satu cara untuk menyelenggarakan pendidikan yang berorientasi pada kecerdasan dan memberikan keleluasan kepada peserta didik untuk mendidik diri mereka sendiri.

Salah satu model pembelajaran yang digunakan untuk menghasilkan lulusan yang kompeten dan kompetitif adalah model pembelajaran Problem Based Learning (PBL). PBL menurut Yanti (2017) merupakan salah satu model pembelajaran yang dapat memberikan kondisi belajar aktif kepada siswa dengan mengarahkan siswa untuk bersama-sama memecahkan suatu masalah. Pengajaran ini menggunakan masalah dunia 
nyata sebagai suatu konteks belajar bagi siswa tentang cara berfikir kritis dan keterampilan pemecahan masalah.

Model pembelajaran tersebut menjadi salah satu pilihan sebab pembelajaran PBL mengajarkan peserta didik mengasah sendiri kemampuan memecahkan masalah melalui kreatifitas yang dimiliki. Melalui penemuan pemecahan masalah tersebut sehingga peserta didik akan lebih mudah mengingat apa yang mereka temukan sendiri daripada dijelaskan secara definisi oleh pendidik. Pendekatan berbasis masalah berkaitan dengan penggunaan intelegensi dari dalam diri individu yang berada dalam sebuah kelompok orang, atau lingkungan untuk memecahkan masalah yang bermakna, relevan dan kontekstual.

Efektivitas model pembelajaran PBL telah dibuktikan oleh beberapa peneliti dalam bidang pendidikan matematika. Tercatat penerapan Model PBL dapat meningkatkan prestasi belajar, kemampuan representasi matematika, dan motivasi belajar (Farhan dan Retnawati, 2014), kemampuan pemecahan masalah matematika (Hidayah, 2015), kemampuan komunikasi dan pemecahan masalah matematika (Yanti, 2016), dan sebagai solusi pembelajaran matematika yang pasif (Royani dan Saufi, 2016).

Keefektifan model pembelajaran PBL dapat didukung dengan aplikasi atau media pembelajaran, sebab media pembelajaran saat ini lebih mudah diakses siswa daripada pembelajaran formal menggunakan buku. Selain itu pembelajaran akan lebih menarik dan lebih berkesan jika menggunakan media pembelajaran, sehingga peserta didik lebih mudah mengerti. Salah satunya yaitu dengan berbasis komputer.

Oleh karena itu dalam penelitian ini digunakan aplikasi Virtual Labobarorium Math untuk membantu mempermudah pembelajaran dengan model PBL pada materi Bangun Ruang di tingkat Sekolah Menengah Pertama. Aplikasi ini akan menayangkan suatu bangun ruang secara 3 dimensi (3D), sehingga diharapkan pembelajaran akan lebih menyenangkan dan tidak monoton, dibandingkan dengan pembelajaran yang hanya dilaksanakan dengan menggunakan papan tulis.

Berdasarkan uraian di atas, maka peneliti merasa perlu untuk melakukan suatu penelitian guna mempelajari efektifitas pembelajaran Problem Based Learning (PBL) menggunakan Aplikasi Virtual Labolatory ditinjau dari hasil belajar dan kemampuan berfikir logis siswa Sekolah Menengah Pertama. 


\section{METODE PENELITIAN}

Penelitian ini merupakan penelitian kuantitatif dengan menggunakan metode kuasi eksperimen (Quasi Experiment). Menurut Sugiyono (2016), metode penelitian kuantitatif dapat diartikan sebagai metode penelitian yang berlandaskan pada filsafat positivism. Jenis penelitian ini digunakan untuk meneliti suatu populasi atau sampel tertentu, melalui pengumpulan data, dengan menggunakan instrumen penelitian. Analisis data yang dilaksanaan bersifat kuantitatif / statistik, dengan tujuan untuk menguji hipotesis yang telah ditetapkan.

Lebih Lanjut dikatakan bahwa metode kuasi eksperimen, sebagaimana penelitian eksperimen, terdapat kelompok siswa yang digolongkan sebagai kelompok control. Namun dalam penelitian ini kontrol yang dilakukan tidak dapat berfungsi sepenuhnya untuk mengontrol variabel-variabel luar yang mempengaruhi pelaksanaan eksperimen. Desain ini digunakan karena pada kenyataannya sulit mendapatkan kelompok kontrol yang digunakan untuk penelitian. Desain eksperimen yang digunakan dalam penelitian ini adalah Desain Kelompok Kontrol Tidak Seimbang (Nonequivalent Control Group Design). Desain ini hampir sama dengan pretest-posttest control group design, hanya pada desain ini kelompok kontrol tidak dipilih secara random tetapi secara berpasangan (Sugiyono, 2011).

Penelitian dilakukan di SMP Muhammadiyah Aimas pada siswa kelas VIII mata pelajaran Matematika. SMP Muhammadiyah Aimas terletak di Kabupaten Sorong tepatnya di kelurahan Malawele. Penelitian dilaksanakan pada bulan Juli-Agustus 2018 pada semester II Tahun Ajaran 2017/2018. Pengambilan data, pelaksanaan pretest, dan observasi dilaksanakan pada bulan Juli, sedangkan pembelajaran, pengisian angket dan post test hasil pembelajaran, dilaksanakan pada Bulan Agustus.

Populasi target adalah siswa Sekolah Menengah Pertama (SMP), dengan populasi terjangkaunya siswa SMP Muhammadiyah Aimas Sorong Tahun Ajaran 2017/2018 dengan jumlah siswa Kelas VIIA sebanyak 19 siswa, Kelas VIIB, sebanyak 15 siswa, Kelas VIIIA, sebanyak 20 siswa, Kelas VIIIB, sebanyak 18 siswa, dan Kelas IX, sebanyak 25 siswa. Sampel dalam penelitian ini adalah siswa kelas VIIIB, yang digunakan sebagai kelas kontrol dengan jumlah siswa 18 orang dan kelas VIIIA, yang bertindak sebagai kelas eksperimen dengan jumlah siswa 20 orang. 
Populasi dapat dikelompokkan menjadi dua, yaitu populasi target dan populasi terjangkau. Populasi target adalah populasi dimana tujuan generalisasi yang hendak dilakukan dalam suatu penelitian, sedangkan populasi terjangkau adalah populasi yang dapat diteliti oleh peneliti (Tanujaya, 2013). Populasi adalah wilayah generalisasi yang terdiri dari atas obyek/subyek yang mempunyai kualitas dan karakteristik tertentu yang ditetapkan oleh peneliti untuk dipelajari dan kemudian ditarik kesimpulannya, sedangkan sampel adalah bagian dari jumlah dan karakteristik yang dimiliki oleh populasi tersebut (Sugiyono, 2015).

Teknik pengambilan sampel yang digunakan adalah purposif (purposive sampling) atau sampel bertujuan, dimana teknik penentuan sampelnya dengan pertimbangan tertentu (Sugiyono, 2011). Beberapa Instrumen pengumpulan data yang digunakan dalam penelitian ini yaitu: Panduan Observasi, Angket, dan Tes. Data yang diperoleh kemudian dianalisis dalam beberapa tahapan analisis, yaitu: uji normalitas, uji homogenitas dan uji t.

Uji Normalitas bertujuan untuk memperlihatkan bahwa data sampel berasal dari populasi yang berdistribusi normal. Hasil pengujian ini akan menunjukkan apakah data dapat digunakan pada tahap analisis selanjutnya. Normalitas data diuji dengan menggunakan uji kolmogorov-smirnov dengan menggunakan paket program program komputer.

Uji homogenitas bertujuan untuk mengetahui apakah data sampel yang diambil dari berasal dari populasi itu bervarians homogen ataukah tidak. Uji yang digunakan menguji homogenitas data adalah analisis ragam (anova), sedangkan uji t digunakan untuk membandingkan rata-rata dari dua kelompok. Uji t yang digunakan untuk melakukan analisis data adalah One Sample $t$ test untuk variabel hasil belajar dan variabel kemampuan berfikir logis, sedangkan untuk menguji kefektifan dari kedua variabel tersebut secara bersama-sama, digunakan T2 Hotelling Trace.

Hasil pengujian tersebut digunakan untuk menarik kesimpulan, apakah kedua kelompok penelitian tersebut mempunyai rata-rata yang sama ataukah tidak secara signifikan, dengan asumsi data berdistribusi normal dan jumlah sampel sedikit (Rusman, 2015). Dengan demikian hipotesis yang diajukan dalam penelitian ini adalah hipotesis dua arah (Ho dan H1), sebagai berikut: 
Ho: Penerapan model Pembelajaran PBL menggunakan aplikasi Virtual Laboratory Math efektif untuk meningkatkan hasil belajar siswa dan kemampuan berpikir logis matematika.

H1: Penerapan model Pembelajaran PBL menggunakan aplikasi Virtual Laboratory Math tidak efektif untuk meningkatkan hasil belajar siswa dan kemampuan berpikir logis matematika.

\section{HASIL DAN PEMBAHASAN}

Sebagaimana dinyatakan sebelumnya, uji statistik pertama yang dilakukan setelah data diperoleh adalah uji normalitas data. Uji Normalitas bertujuan untuk menguji apakah data hasil pretes dan postes berasal dari populasi yang distribusi normal atau tidak. Pengujian normalitas dilakukan dengan menggunakan metode statistika non parametric, yaitu Uji Kolmogrof Smirnov. Hasil uji normalitas pada kedua gugus data tersebut secara terinci disajikan pada Tabel 1.

\section{Tabel 1. Hasil Analisis Normalitas untuk Data Pretes dan Postes}

\begin{tabular}{ccccc}
\hline \multicolumn{4}{c}{ Probabilitas Kolmogorof Smirnof } & \multirow{2}{*}{$\boldsymbol{\alpha}$} \\
\cline { 1 - 4 } \multicolumn{2}{c}{ Pretes } & \multicolumn{2}{c}{ Postes } & \multirow{2}{*}{0,05} \\
\hline HB & KBL & HB & KBL & \\
\hline 0,242 & 0,795 & 0,939 & 0,508 & \\
\hline
\end{tabular}

Berdasarkan hasil uji normalitas, sebagaimana tampak pada Tabel 1, diketahui bahwa hasil belajar (HB) dari Pretes memiliki probabilitas sebesar 0,242, sedangkan kemampuan berfikir logisnya (KBL) sebesar 0,795. Berdasarkan hasil analisis tersebut, tampak bahwa kedua nilai tersebut lebih besar dari nilai $\alpha=0,05(0,242>0,5$, dan 0,795 $>0,05)$. Dengan demikian berdasarkan hasil pretes dapat disimpulkan bahwa data berasal dari populasi yang berdistribusi normal.

Hasil yang tidak berbeda juga ditunjukkan pada data postes, dimana nilai probabilitas untuk hasil belajar sebesar 0,939, sedangkan untuk kemampuan berfikir logis sebesar 0,508. Kedua nilai probabilitas tersebut lebih besar dari nilai alpha $(0,939>0,05$, $0,508>0,05)$, sehingga dapat dinyatakan bahwa data Postes yang digunakan berasal dari populasi berdistribusi normal. Dengan kata lain analisis lebih lanjut terutama tentang homogenitas data dapat dilakukan.

Uji homogenitas sampel digunakan untuk menguji apakah sampel yang digunakan homogen atau tidak. Uji yang digunakan yaitu menggunakan uji ANOVA, dengan hasil 
analisis sebagaimaan disajikan pada Tabel 2.

Tabel 2. Hasil ANOVA untuk Data Pretes dan Postes

\begin{tabular}{cccccc}
\hline \multicolumn{4}{c}{ Signifikasi ANOVA } & \multirow{2}{*}{$\boldsymbol{\alpha}$} & \multirow{2}{*}{ F tabel } \\
\hline \multicolumn{2}{c}{ Nilai } & \multicolumn{2}{c}{ F Hitumg } & & \\
\cline { 1 - 4 } HB & KBL & HB & KBL & \multirow{2}{*}{0,05} & \multirow{2}{*}{3,59} \\
\hline 0,511 & 0,321 & 0,704 & 0,094 & & \\
\hline
\end{tabular}

Berdasarkan hasil uji ANOVA, sebagaimana tampak pada Tabel 2, didapatkan hasil dari nilai tes memiliki signifikasi hasil belajar 0,511, dengan $\mathrm{F}$ hitung yang lebih besar dari $\mathrm{F}$ tabel $(0,704<3,59)$, sedangkan untuk kemampuan berfikir logis diperoleh nilai sebesar $0,321(0,321>0,05)$ dengan $\mathrm{F}$ hitung 0,094 , yang juga lebih besar dari $\mathrm{F}$ tabel $(0,094<3,59)$. Berdasarkan hasil analisis tersebut, dapat disimpukan bahwa sampel yang digunakan mempunyai sebaran yang homogen. Deangan demikian maka uji statistika untuk mempelajari efektifitas model pembelajaran PBL dalam penelitian ini dapat dilakukan.

Uji t digunakan untuk menguji keefektifan model Pembelajaran PBL menggunakan aplikasi VR Math terhadap hasil belajar dan kemampuan berfikir logis siswa. Uji t yang digunakan untuk melakukan analisis data adalah One Sample t Test untuk variabel hasil belajar dan variabel kemampuan berfikir logis, sedangkan untuk menguji kefektifan dari kedua variabel digunakan T2 Hotelling Trace.

\section{Uji One Sample t test}

Uji One Sample $t$ test untuk menguji keefektifan model Pembelajaran PBL menggunakan aplikasi VR Math terhadap hasil belajar siswa disajikan pada Tabel 3.

Tabel 3. Hasil Uji Efeketifitas Tes Hasil Belajar

\begin{tabular}{cccc}
\hline Nilai T Tabel & Nilai T hitung & Signifikasi & $\boldsymbol{\alpha}$ \\
\hline 1.740 & -0.777 & 0,447 & 0,05 \\
\hline
\end{tabular}

Berdasarkan hasil analisis data sebagaimana disajikan pada Tabel 3, diperoleh bahwa nilai $\mathrm{t}$ hitung $=-0,777$. Nilai $\mathrm{t}$ hitung yang diperoleh tersebut $(|-0.777|=0.777)$, adalah lebih kecil dari nilai t tabel (1.740), atau dapat dikatakan bahwa thitung $<\mathrm{t}$ tabel. Dengan demikian dapat dapat dinyatakan bahwa tidak cukup bukti untuk menolak Ho. Berdasarkan hasil analisis tersebut, maka dapat disimpulkan bahwa penerapan model Pembelajaran PBL menggunakan aplikasi VR Math tidak efektif untuk meningkatkan 
hasil belajar siswa.

Lebih lanjut, uji One Sample t test juga dilakukan untuk menguji keefektifan model Pembelajaran PBL menggunakan aplikasi VR Math terhadap kemampuan berfikir logis, disajikan pada Tabel 4.

Tabel 4. Hasil Uji Efeketivitas Kemampuan Berfikir Logis

\begin{tabular}{cccc}
\hline Nilai T Tabel & Nilai T hitung & Signifikasi & $\boldsymbol{\alpha}$ \\
\hline 1.740 & $-9,160$ & 0,000 & 0,05 \\
\hline
\end{tabular}

Berdasarkan hasil analisis data sebagaimana disajikan pada Tabel 4, diperoleh bahwa nilai t hitung $=-9,160$. Nilai t hitung yang diperoleh tersebut $(|-9.160|=9.160)$, adalah lebih besar dari nilai $t$ tabel (1.740), atau dapat dikatakan bahwa $t$ hitung $>t$ tabel. Dengan demikian dapat dinyatakan bahwa terdapat cukup bukti untuk menolak Ho. Dengan demikian dapat disimpulkan bahwa model Pembelajaran PBL menggunakan aplikasi VR Math efektif untuk meningkatkan kemampuan berfikir logis siswa.

\section{T2 Hotteling Test,}

Uji T2 Hotteling Trace digunakan untuk menguji keefektifan model Pembelajaran PBL menggunakan aplikasi VR Math terhadap hasil belajar dan kemampuan berfikir logis siswa. Hasil analisis data tersebut disajikan pada Tabel 5.

Tabel 5. Hasil Uji Hotteling Trace

\begin{tabular}{cc}
\hline Signifikasi & $\boldsymbol{\alpha}$ \\
\hline 0.000 & 0.05 \\
\hline
\end{tabular}

Berdasarkan hasil analisis sebagaimana tampak pada Tabel 5., diperoleh bahwa signifikasi Hotteling Trace $=0,000$. Berdasarkan hasil analisis data tersebut maka dapat dinyatakan bahwa terdapat cukup bukti untuk menolak $\mathrm{H}_{0}$. Dengan demikian dapat disimpulkan bahwa model Pembelajaran PBL yang menggunakan aplikasi VR Math efektif terhadap peningkatan hasil belajar dan kemampuan berfikir logis siswa SMP.

\section{SIMPULAN}

Berdasarkan hasil penelitian yang dilaksanakan di SMP Muhammadiyah Aimas, Kabupaten Sorong, Provinsi Papua Barat, tentang efektifitas model pembelajaran PBL menggunakan aplikasi VR Math untuk terhadap hasil belajar dan kemampuan berfikir logis siswa dapat disimpulkan bahwa model pembelajaran PBL menggunakan aplikasi VR Math tidak efektif ditinjau dari hasil belajar siswa, tetapi efektif jika ditinjau dari 
kemampuan berfikir logis siswa. Selain itu diketahui juga bahwa Model pembelajaran PBL menggunakan aplikasi VR Math efektif ditinjau dari hasil belajar dan kemampuan berfikir logis siswa, berdasarkan uji Hotteling Trace.

\section{DAFTAR RUJUKAN}

Agustin, R. D. (2016). Kemampuan Penalaran Matematika Mahasiswa melalui Pendekatan Problem Solving. Jurnal Pedagogi, 5(2): 179-188.

Farhan, M., dan H. Retnawati. (2014). Keefektivan PBL dan IBL Ditinjau dari Prestasi Belajar, Kemampuan Representasi Matematis, dan Motivasi Belajar. Jurnal Riset Pendidikan Matematika, 1 (2): 227 - 240.

Kemendikbud. (2016). Kemendikbud Rilis Hasil Ujian Nasional Perbaikan. Jakarta: Biro Komunikasi dan layanan Masyarakat, Kemendikbud.

Chaeruman, U. A. (2018). Pembelajaran di Era Abad 21. Seminar Nasional Pembelajaran Abad 21, Sawangan: Pusdiklat Kemendikbud.

Haryono A., dan B. Tanujaya. (2018). Profil Kemampuan Penalaran Induktif Matematika Mahasiswa Pendidikan Matematika UNIPA Ditinjau dari gaya Belajar. Journal of Honai Math, 1 (2): 127 - 138. DOI: 10.30862/jhm.vli2.1049.

Hidayah M. (2015). Penerapan Problem Based Learning dalam Pembelajaran Matematika untuk Meningkatkan Kemampuan Pemecahan Masalah pada Siswa Kelas VIII Semester II SMPN 1 Teras Tahun 2014/2015. Skripsi. Surakarta: Universitas Muhammadiyah Surakarta.

Joice, B., M. Weil, dan E. Calhoun. (2011). Model of Teaching, Model-model Pengajaran. Yogyakarta: Pustaka Pelajar.

Royani, H.M., dan M. Saufi. (2016). Problem Based Learning: Solusi Pembelajaran Matematika yang Pasif. Math Dicdatic: Jurnal Pendidikan Matematika. 2 (2): 127 -131 .

Rusman, T. (2015). Statistika Penelitian. Yogyakarta: Graha Ilmu

Siing. M. (2017). Peran Guru di Era Globalisasi Pendidikan. https://www.kompasiana.com/msiing/5935e795ed967e098b218922/peran-guru-diera-globalisasi-pendidikan?page=all, diakses 02 November 2018.

Sugiyono. (2011). Metode Penelitian Bisnis. Bandung: Alfabeta

Sugiyono. (2015). Metode Peneltian Kombinasi. Bandung: Alfabeta

Sugiyono. (2016). Metode Penelitian Pendidikan: Pendekatan Kuantitatif, Kualitatif, dan $R \& D$. Bandung: Alfabeta.

Tanujaya, B. (2013). Penelitian Percobaan. Bandung: Remaja Rosdakarya. 
Astutik \& Aniningsih, Efektivitas pembelajaran PBL berbantuan VL ditinjau dari hasil belajar dan kemampuan berpikir logis matematika siswa SMP

Yanti, A. H. (2017). Penerapan Model Problem Based Learning (PBL) terhadap Kemampuan Komunikasi dan Kemampuan Pemecahan Masalah Matematika Siswa Sekolah Menengah Pertama Lubuklinggau. 